\title{
KETEPATAN KLASIFIKASI STATUS DIABETES MELITUS DENGAN PENDEKATAN MULTIVARIATE ADAPTIVE REGRESSION SPLINE
}

\author{
Herlina Jusuf $^{(1)}$, Bambang Widjanarko Otok ${ }^{(2)}$, Amanda Ratna Ningrum ${ }^{(3)}$ \\ ${ }^{(1)}$ Faculty Science Health and Sportmanship, University Country of Gorontalo, Gorontalo \\ ${ }^{(2),(3)}$ Department of Statistics, 'Sepuluh Nopember' Institute of Technology (ITS), Surabaya \\ Alamat \\ e-mail: ${ }^{(1)}$ herlina_jusuf@yahoo.co.id, ${ }^{(2)}$ dr.otok.bw@ gmail.com
}

\begin{abstract}
ABSTRAK
Diabetes Mellitusadalah suatu penyakit gangguan metabolik akut yang ditandai oleh kadar glukosa darah melebihi nilai normal. Diabetes Mellitus merupakan suatu penyakit atau kelainan yang mempengaruhi kemampuan tubuh untuk mengubah makanan menjadi energy. Dengan semakin meningkatnya prevalensi kasus penyakit Diabetes Mellitus, maka tujuan penelitian ini adalah memprediksi variabel apa saja yang berperan sangat besar sebagai salah satu faktor risiko kejadian Diabetes Mellitus. Hasil penelitian menunjukkan bahwa status diabetes mellitus terdapat hubungannya dengan obesitas, hipertensi dan kebiasaan olahraga, sedangkan dengan pendekatan MARS melalui criteria GCV terkecil dan (R-O) ${ }^{2}$ terbesar diperoleh factor yang mempengaruhi status diabetes mellitus adalah obesitas dan hipertensi dengan ketepatan klasifikasi sebesar 74.0 persen.
\end{abstract}

Kata kunci : Diabetes Mellitus, Obesitas, Hipertensi,MARS

\section{PENDAHULUAN}

Diabetes mellitus (DM) merupakan penyakit metabolik yang ditandai dengan peningkatan kadar gula darah akibat gangguan pada sekresi insulin, kerja insulin atau keduanya. Terdapat 3 kategori DM, yaitu tipe 1, tipe 2, dan diabetes gestasional. Diabetes tipe 2 yang umumnya timbul akibat resistensi insulin terkait perubahan gaya hidup. Penderita DMtipe 2 sebanyak 90 persen dari semua kasus (Depkes, R. I., 2013).

DM juga memberikan dampak bagi pasien diantaranya adalah dampak fisik dan dampak psikologis. Dampak fisik yaitu retinopati diabetic, nefropati diabetic, dan neuropati diabetic. Salah satu dampak psikologis yang sering terjadi adalah kecemasan. Kecemasan adalah suatu reaksi emosional yang timbul oleh penyebab tidak pasti dan tidak spesifik yang dapat menimbulkan perasaan tidak nyaman dan merasa terancam. Tindakan yang dapat diberikan pada pasien yang mengalami kecemasan adalah penyuluhan dan terapi $P M R$. Hasil penelitian yang dilakukan (Yildrim, A., dkk, 2007) menyebutkan bahwa PMR menurunkan kecemasan dan meningkatkan kualitas hidup pasien yang menjalani dialisis.

International Diabetes Federation (IDF) menyatakan bahwa pada tahun 2005 terdapat 200 juta $(5.1 \%)$ orang dengan diabetes (diabetes) di dunia, dan diduga 20 tahun kemudian yaitu 2025 akan meningkat menjadi 333 juta $(6.3 \%)$ orang. Negara seperti India, China, Amerika Serikat, Jepang, Indonesia, Pakistan, Bangladesh, Italia, Rusia, Dan Brazil Merupakan 10 besar Negara dengan jumlah penduduk diabetes terbanyak (WHO, 2004).

Menurut(WHO, 2015) diperkirakan angka prevalensi kasus Diabetes di seluruh dunia pada tahun 2030 sebanyak 366.000.000 kasus. Sementara di Indonesia diperkirakan sebanyak 21.257.000 kasus.Berdasarkan data Badan Pusat Statistik Indonesia (2003) diperkirakan penduduk Indonesia yang berusia di atas 20 tahun adalah sebesar 133 juta jiwa. Dengan prevalensi DM pada daerah urban sebesar $14,7 \%$ dan daerah rural sebesar 7,2\%, maka diperkirakan pada tahun 2003 terdapat penyandang diabetes sejumlah 8,2 juta di daerah urban dan 5,5 juta di daerah rural. Selanjutnya, berdasarkan pola pertambahan penduduk, diperkirakan pada tahun 2030 nanti akan ada 194 juta penduduk yang berusia di atas 20 tahun dan dengan asumsi prevalensi DM pada urban $(14,7 \%)$ dan rural $(7,2 \%)$ maka diperkirakan terdapat 12 juta penyandang diabetes di daerah urban dan 8,1 juta di daerah rural. Suatu jumlah yang sangat besar dan merupakan beban yang sangat berat untuk dapat ditangani sendiri oleh dokter spesialis/ subspesialis bahkan oleh semua tenaga kesehatan yang ada. Mengingat bahwa DM akan memberikan dampak terhadap

Herlina Jusuf ${ }^{1}$, Bambang Widjanarko Otok ${ }^{2}$, Amanda Ratna Ningrum ${ }^{3} /$ J Statistika Vol. 9, No. 1, (2016) 
kualitas sumber daya manusia dan peningkatan biaya kesehatan yang cukup besar (Suyono, S., 2013).

Laporan hasil Riset Kesehatan Dasar (Riskesdas) tahun 2007 oleh Departemen Kesehatan, menunjukkan bahwa prevalensi DM di daerah urban Indonesia untuk usia diatas 15 tahun sebesar 5,7\%. Prevalensi terkecil terdapat di Propinsi Papua sebesar 1,7\%, dan terbesar di Propinsi Maluku Utara dan Kalimanatan Barat yang mencapai $11,1 \%$. Sedangkan prevalensi toleransi glukosa terganggu (TGT), berkisar antara 4,0\% di Propinsi Jambi sampai 21,8\% di Propinsi Papua Barat(Suyono, S., 2013).

Dengan semakin meningkatnya prevalensi kasus penyakit degeneratif, salah satunya penyakit Diabetes Mellitus, maka peneliti ingin memprediksi variabel apa saja yang berperan sangat besar sebagai salah satu faktor risiko kejadian Diabetes Mellitus(American Diabetes Association, 2011). Dengan mengetahui secara jelas faktor risiko yang berperan terhadap kejadian Diabetes Mellitus diharapkan dapat dijadikan sebagai acuan upaya pencegahan dan pengendalian kasus Diabetes Mellitus, sehingga dapat menurunkan prevalensi Diabetes Mellitus, dan mencegah kematian akibat penyakit degeneratif, khususnya Diabetes Mellitus.

\section{METODE PENELITIAN}

Jenis penelitian yang digunakan adalah penelitian Non Reactive (unobstrutive)(Sekaran, U.,2011), menggunakan data sekunder berupa dokumen yang ada di form RS Dunda Gorontalo. Data tersebut merupakan data yang dikumpulkan oleh tenaga kesehatan yang sesuai dengan form pertanyaan yang ada di form posbindu dan peneliti tidak terlibat langsung dalam mendapatkan informasi dari subjek penelitian. Variabel penelitian meliputi variable respond dan prediktor. Variabel dependen (respon) yaitu status diabetes mellitus, variabel independen (prediktor) yaitu riwayat genetik, hipertensi, dan obesitas, sedangkan kovariat adalah kebiasaan olahraga. Kerangka konsep factor-faktor yang mempengaruhi kejadian Diabetes Mellitus sebagai berikut:

Langkah pertama, dilakukan analisis statistik deskriptif terhadap variabel-veriabel perdiktor. Kedua, untuk mengetahui faktor-faktor apa saja yang mempengaruhi status diabetes mellitus, dilakukan prosedur berikut (Otok, B.W.,dkk, 2007)

1. Pembentukan model MARS untuk data set awal: (1) menentukan $B F$; (2) menentukan $M I$; (3) menentukan $M O$ di antara knot.

2. Mendapatkan model MARS terbaik untuk dataset tunggal berdasarkan nilai $G C V$ terkecil.
3. Mendapatkan variabel yang signifikan berpengaruh dari model $A R S$ terbaik untuk dataset tunggal.

Model MARS berguna untuk mengatasi permasalahan data berdimensi tinggi dan menghasilkan prediksi variabel respon yang akurat, dan menghasilkan model yang kontinu dalam knot berdasarkan nilai GCV terkecil (Friedman, J.H. and Silverman, B.W., 1989).

\section{HASIL DAN PEMBAHASAN}

Deskripsi penelitian ini meliputi distribusi frekuensi dan uji independensi antar variabel. Adapun secara rinci disajikan pada Tabel berikut:

Tabel 1. Deskripsi \&uji independensi status diabetes mellitusdengan variabel independen

\begin{tabular}{|c|c|c|c|}
\hline \multirow{2}{*}{\multicolumn{2}{|c|}{$\begin{array}{l}\text { Frekuensi\% Total } \\
\text { Pearson Chi-Square }\end{array}$}} & \multicolumn{2}{|c|}{ Status Diabetes Melitus } \\
\hline & & \multirow{2}{*}{$\begin{array}{c}\mathrm{Ya} \\
21 \\
(3.1)\end{array}$} & \multirow{2}{*}{$\begin{array}{c}\text { Tidak } \\
41 \\
(-3.1)\end{array}$} \\
\hline \multirow{3}{*}{$\begin{array}{l}\text { Aktivitas } \\
\text { Olahraga }\end{array}$} & Kurang & & \\
\hline & Cukup & $\begin{array}{c}2 \\
(-3.1) \\
\end{array}$ & $\begin{array}{c}32 \\
(3.1)\end{array}$ \\
\hline & \multicolumn{3}{|c|}{$\begin{array}{l}\text { Pearson Chi-Square }=9.442 \mathrm{df}=1 \\
\text { Asymptotic Significance }(2 \text {-sided })= \\
0.002\end{array}$} \\
\hline \multirow{3}{*}{$\begin{array}{l}\text { Riwayat } \\
\text { Genetik }\end{array}$} & Ya & $\begin{array}{c}5 \\
(0.3)\end{array}$ & $\begin{array}{c}14 \\
(-0.3)\end{array}$ \\
\hline & Tidak & $\begin{array}{c}18 \\
(-0.3)\end{array}$ & $\begin{array}{c}59 \\
(0.3)\end{array}$ \\
\hline & \multicolumn{3}{|c|}{$\begin{array}{l}\text { Pearson Chi-Square }=0.072 \mathrm{df}=2 \\
\text { Asymptotic Significance }(2 \text {-sided })= \\
0.788\end{array}$} \\
\hline \multirow{3}{*}{ Hipertensi } & Ya & $\begin{array}{c}16 \\
(3.2)\end{array}$ & $\begin{array}{c}23 \\
(-3.2) \\
\end{array}$ \\
\hline & Tidak & $\begin{array}{c}7 \\
(-3.2)\end{array}$ & $\begin{array}{c}50 \\
(3.2)\end{array}$ \\
\hline & \multicolumn{3}{|c|}{$\begin{array}{l}\text { Pearson Chi-Square }=10.502 \mathrm{df}=1 \\
\text { Asymptotic Significance }(2 \text {-sided })= \\
0.001\end{array}$} \\
\hline \multirow{3}{*}{ Obesitas } & Ya & $\begin{array}{c}18 \\
(4.1)\end{array}$ & $\begin{array}{c}22 \\
(-4.1)\end{array}$ \\
\hline & Tidak & $\begin{array}{c}5 \\
(-4.1)\end{array}$ & $\begin{array}{c}51 \\
(4.1) \\
\end{array}$ \\
\hline & \multicolumn{3}{|c|}{$\begin{array}{l}\text { Pearson Chi-Square }=16.665 \mathrm{df}=1 \\
\text { Asymptotic Significance }(2 \text {-sided })= \\
0.000\end{array}$} \\
\hline
\end{tabular}

Tabel 1 menunjukan bahwa sebagian besar pasien rawat inap mempunyai status tidak diabetes mellitus yaitu sebesar 76.04 persen, dan ada diabetes mellitus sebesar 23.96 persen. Selain itu dapat ditunjukkan bahwa semua nilai Asymptotic Significance (2-sided) lebih kecil dari $\alpha=0.05$ kecuali pada riwayat genetic, maka terdapat hubungan antara aktivitas olahraga, hipertensi dan obesitas dengan status diabetes mellitus. Sedangkan dengan riwayat genetik tidak terdapat hubungan dengan status diabetes mellitus.

Pemilihan model terbaik diperoleh dengan cara membandingkan nilai GCV dan nilai (R-O) ${ }^{2}$. Nilai GCV terkecil dan nilai $\mathrm{R}^{2}$ terbesar adalah model terbaik. Perbandingan dilakukan pada berbagai jumlah basis fungsi $(\mathrm{BF}=19,38$ dan 57), dan berbagai maksimum interaksi $(\mathrm{MI}=1,2$ dan 3) dan berbagai minimum observasi

Herlina Jusuf ${ }^{1}$, Bambang Widjanarko Otok ${ }^{2}$, Amanda Ratna Ningrum ${ }^{3}$ / J Statistika Vol. 9, No. 1, (2016) 
( $\mathrm{MO}=0,1,2,3,5,10)$. Semua kemungkinan model yang telah dicobakan didapatkan model terbaiknya dengan kriteria model yang memiliki nilai GCV terkecil dan $\mathrm{R}-\mathrm{O}^{2}$ yang besar. Secara rinci pemilihan model terbaik disajikan pada Tabel 2.

Tabel 2. Model terbaik status diabetes mellitus berbagai BF, MI, MO berdasarkan $\mathrm{GCV}, \mathrm{R}-\mathrm{O}^{2}$

\begin{tabular}{|c|c|c|c|c|c|c|}
\hline $\begin{array}{l}\mathbf{N} \\
\mathbf{o}\end{array}$ & $\begin{array}{l}\mathbf{B} \\
\mathbf{F} \\
\end{array}$ & $\begin{array}{l}\mathbf{M} \\
\mathbf{I}\end{array}$ & $\begin{array}{l}\mathbf{M} \\
\mathbf{O}\end{array}$ & $\begin{array}{c}\text { GC } \\
\text { V }\end{array}$ & $\mathrm{R}-\mathrm{O}^{2}$ & Model Prediksi \\
\hline 1 & 8 & 1 & 0 & 0.160 & 0.957 & $\begin{array}{l}\mathrm{Y}=1.975-0.309 \\
\mathrm{BF} 1-0.211 \text { * } \mathrm{BF} 3 \\
\mathrm{ZBF} 1=(\mathrm{OBS}=1) ; \\
\mathrm{BF} 3=(\mathrm{HT}=1)\end{array}$ \\
\hline 5 & 8 & 2 & 0 & $\begin{array}{c}0.1 \\
62\end{array}$ & 0.956 & $\begin{array}{l}\mathrm{Y}=1.865-0.456 \text { * } \\
\mathrm{BF} 3 \\
\quad \mathrm{BF} 1=(\mathrm{OBS}=1) ; \\
\mathrm{BF} 3=(\mathrm{HT}=1) \star \mathrm{BF} 1\end{array}$ \\
\hline 9 & 8 & 3 & 0 & $\begin{array}{c}0.1 \\
62\end{array}$ & 0.956 & $\begin{array}{l}\mathrm{Y}=1.865-0.456 \text { * } \\
\mathrm{BF} 3 \\
\mathrm{BF} 1=(\mathrm{OBS}=1) ; \\
\mathrm{BF} 3=(\mathrm{HT}=1) \star \mathrm{BF} 1\end{array}$ \\
\hline $\begin{array}{l}1 \\
3\end{array}$ & $\begin{array}{l}1 \\
2\end{array}$ & 1 & 0 & $\begin{array}{c}0.1 \\
68\end{array}$ & 0.954 & $\begin{array}{l}\mathrm{Y}=1.911-0.361 * \\
\mathrm{BF} 1 \\
\mathrm{BF} 1=(\mathrm{OBS}=1) ;\end{array}$ \\
\hline $\begin{array}{l}1 \\
7\end{array}$ & $\begin{array}{l}1 \\
2\end{array}$ & 2 & 0 & $\begin{array}{c}0.1 \\
62\end{array}$ & 0.956 & $\begin{array}{l}\mathrm{Y}=1.865-0.456 \text { * } \\
\mathrm{BF} 3 \\
\mathrm{BF} 1=(\mathrm{OBS}=1) ; \\
\mathrm{BF} 3=(\mathrm{HT}=1) \star \mathrm{BF} 1\end{array}$ \\
\hline $\begin{array}{l}2 \\
1\end{array}$ & $\begin{array}{l}1 \\
2\end{array}$ & 3 & 0 & $\begin{array}{c}0.1 \\
62\end{array}$ & 0.956 & $\begin{array}{l}\mathrm{Y}=1.865-0.456 \text { * } \\
\mathrm{BF} 3 \\
\mathrm{BF} 1=(\mathrm{OBS}=1 ; \\
\mathrm{BF} 3=(\mathrm{HT}=1) \star \mathrm{BF} 1\end{array}$ \\
\hline $\begin{array}{l}2 \\
5\end{array}$ & $\begin{array}{l}1 \\
6\end{array}$ & 1 & 0 & $\begin{array}{c}0.1 \\
71\end{array}$ & 0.954 & $\begin{array}{l}\mathrm{Y}=1.911-0.361 \text { * } \\
\mathrm{BF} 1 \\
\mathrm{BF} 1=(\mathrm{OBS}=1)\end{array}$ \\
\hline $\begin{array}{l}2 \\
9\end{array}$ & $\begin{array}{l}1 \\
6\end{array}$ & 2 & 0 & $\begin{array}{c}0.1 \\
62\end{array}$ & 0.956 & $\begin{array}{l}\mathrm{Y}=1.865-0.456 \text { * } \\
\mathrm{BF} 3 \\
\mathrm{BF} 1=(\mathrm{OBS}=1) ; \\
\mathrm{BF} 3=(\mathrm{HT}=1) \star \mathrm{BF} 1\end{array}$ \\
\hline $\begin{array}{l}3 \\
3\end{array}$ & $\begin{array}{l}1 \\
6\end{array}$ & 3 & 0 & $\begin{array}{c}0.1 \\
68\end{array}$ & 0.954 & $\begin{array}{l}\mathrm{Y}=1.911-0.361 \text { * } \\
\mathrm{BF} 1 \\
\mathrm{BF} 1=(\mathrm{OBS}=1)\end{array}$ \\
\hline
\end{tabular}

Tabel 2, menunjukkan model terbaik dengan kriteria GCV terkecil dan $\mathrm{R}^{2}$ terbesar yaitu semua model, baik yang melibatkan jumlah basis fungsi 8, 12 dan 16. Sehingga untuk parsimoni model dipilih model ke-1 dengan jumlah $\mathrm{BF}=8, \mathrm{MI}=1$, dan $\mathrm{MO}=0$ dengan nilai GCV sebesar 0.160 dan $(\mathrm{R}-\mathrm{O})^{2}=0,957$. Model MARS terbaik yang didapatkan dinyatakan dalam persamaan sebagai berikut.

dimana

$$
\mathrm{Y}=1.975-0.309 * \mathrm{BF} 1-0.211 * \mathrm{BF} 3
$$

$\mathrm{BF} 1=(\mathrm{OBS}=1)$

$\mathrm{BF} 3=(\mathrm{HT}=1)$ berikut.

Interpretasi model ARS adalah sebagai

- $\quad \mathrm{BF} 1=(\mathrm{OBS}=1)$

Artinya, koefisien BF1 akan bermakna jika pasien mempunyai obesitas maka setiap kenaikan $\pi(x)=\frac{e^{(1,975-0,309 B F 1)}}{1+e^{(1,975-0,309 B F 1)}}=\frac{e^{(1,975-0,309(1))}}{1+e^{(1,975-0,309(1))}}=0,841$ satu basis fungsi (BF1) dapat menurunkandiabetes sebesar 0,309. Atau jika pasienada obesitas maka peluang pasienmenderita Diabetes Melitus sebesar

\section{- $\quad \mathrm{BF} 3=(\mathrm{HT}=1)$}

Artinya, koefisien BF3 akan bermakna jika pasien mempunyai hipertensi maka setiap kenaikan satu basis fungsi (BF3) dapat menurunkandiabetes sebesar 0,211. Atau jika pasienhipertensi maka peluang pasienmenderita Diabetes Melitus sebesar

$$
\pi(x)=\frac{e^{(1,975-0,211 B F 3)}}{1+e^{(1,975-0,211 B F 3)}}=\frac{e^{(1,975-0,211(1))}}{1+e^{(1,975-0,211(1))}}=0,854
$$

Ketepatan klasifikasi digunakan untuk mengetahui seberapa besar peluang ketepatan model dalam pengklasifikasian status DM dengan menghitung nilai Sensitivity, Specificity, Total Accuracy. Berikut hasil ketepatan klasifikasi dengan menggunakan MARS berdasarkan faktorfaktor yang mempengaruhi status DM

Tabel 3. Hasil klasifikasi model MARS

\begin{tabular}{|l|c|c|c|c|c|}
\hline \multirow{2}{*}{$\begin{array}{l}\text { Kelompok } \\
\text { Observasi }\end{array}$} & \multicolumn{2}{|c|}{ Status DM } & Total & & \\
\cline { 2 - 6 } & DM & $\begin{array}{c}\text { Tidak } \\
\text { DM }\end{array}$ & $\begin{array}{c}\text { Sensi- } \\
\text { tivity }\end{array}$ & $\begin{array}{c}\text { Speci- } \\
\text { ficity }\end{array}$ \\
\hline DM & 20 & 3 & 23 & 87.0 & \\
\hline Tidak DM & 22 & 51 & 73 & & 69.9 \\
\hline \multicolumn{7}{|l}{ Ketepatan Klasifikasi } & 74.0 & & \\
\hline
\end{tabular}

Tabel 3. menunjukkan bahwa ketepatan klasifikasi status diabetes mellitus sebesar 74.0 persen dengan sensitifitas sebesar 87.0 persen, dan spesifisitas sebesar 69.9 persen.

\section{KESIMPULAN DAN SARAN}

Berdasarkan analisis dan pembahasan tentang faktor-faktor yang mempengaruhi status diabetes mellitus di Rumah SakitDunda Gorontalo, maka dapat disimpulkan bahwa obesitas, hipertensi dan kebiasaan olahraga terdapat hubungan dengan status diabetes mellitus, sedangkan factor yang mempengaruhi adalah obesitas dan hipertensi dengan ketepatan klasifikasi sebesar 74 persen, sensitifitas sebesar 87 persen dan spesifisitas sebesar 69.9 persen. Peluang terjadi diabetes mellitus disebabkan hipertensi sebesar 85.4 persen, sedangkan disebabkan obesitas sebesar 84.1 persen.

\section{DAFTAR PUSTAKA}

Herlina Jusuf ${ }^{1}$, Bambang Widjanarko Otok ${ }^{2}$, Amanda Ratna Ningrum 3 / J Statistika Vol. 9 , No. 1, (2016) 
American Diabetes Association. (2011). Diagnosis and Classification Of Diabetes Mellitus. Diabetes Care, 9, 34-62.

Depkes, R. I. (2013). Riset Kesehatan Dasar 2013. Jakarta: Depkes RI.

Friedman, J.H. and Silverman, B.W. (1989).Flexible Parsimony Smoothing and Additive Modelling. Technometrics, 31.

Otok, B.W. (2008). Bootstrap Pada Pemodelan Multivariat Adaptive Regression Spline. Disertasi UGM. Yogyakarta. (tidak dipublikasikan)

Otok, B.W., M. Sjahid Akbar, Suryo Guritno dan Subanar, (2007), Ordinal Regression Model using Bootstrap Approach, Jurnal ILMU DASAR, Vol. 8 No. 1, 2007 : 54-67, UNEJ - Jember.

Sekaran, U. (2011). Metodologi Penelitian $\left(4^{\text {th }}\right.$ ed.). Jakarta: Salemba

Suyono, S. (2013). Kecenderungan Peningkatan Jumlah Penyandang Diabetes. Jakarta: FKUI.

WHO. (2004). Introducing the WHOQOL Instruments. Diakses pada 18 Januari 2016, dari http://dept.washington.edi/yqol/docs/who qol_infopf.

WHO. (2015). Massage on Wordl Diabetes Day. Diakses pada 20 Januari 2016, dari http://www.who.int/diabetes/SG_ message_WDD2015.pdf?ua=1..

Yildrim, A., Akinci, F., Gozu, H., Sargin, H., Obey, E., \& Sargin, M. (2007). Translation, Cultural Adaptation, CrossValidation of The Turkish Diabetes Quality of Life (DQOL) Measure. Quality Life Research, 16(5), 873-879. Diakses pada 27 Januari 2016, dari http://www.jstor.org/stable /27641317.

Herlina Jusuf ${ }^{1}$, Bambang Widjanarko Otok ${ }^{2}$, Amanda Ratna Ningrum ${ }^{3}$ / J Statistika Vol. 9, No. 1, (2016) 